\title{
Dos desafios institucionais para a realização dos direitos fundamentais sociais no contexto das políticas públicas
}

\author{
Institutional challenges to achieving the fundamental social rights in the context of public \\ policy
}

\author{
Victor Hugo Siqueira de Assis ${ }^{1}$
}

\section{Resumo}

O presente trabalho objetiva analisar o crescente papel do Judiciário no controle das políticas públicas e sua repercussão sobre o tema da eficácia dos direitos fundamentais sociais. A Constituição Federal de 1988 assegura a aplicação imediata dos direitos fundamentais, independentemente de sua feição e mesmo que não estejam expressamente consignados em seu texto. A despeito disso, é inegável a dificuldade enfrentada quando se trata de direitos sociais, caracterizados por necessitarem de prestações positivas por parte do Estado. Diante desse panorama, analisa-se se o princípio da reserva do possível pode ser aplicado ao ordenamento jurídico brasileiro como forma de justificar determinadas escolhas trágicas, além de sua ligação com o conceito de mínimo existencial. Por fim, é estudada a importante discussão travada acerca da possibilidade e dos limites da atuação do Judiciário no controle dessas políticas públicas desenvolvidas pelo Executivo e Legislativo.

Palavras-Chave: Direitos fundamentais sociais; Efetividade reserva do possível; Mínimo existencial; Políticas públicas; Controle judicial.

\begin{abstract}
This paper analyzes the growing role of the judiciary in the control of public policies and their impact on the issue of effectiveness of fundamental social rights. The 1988 Constitution guarantees the immediate application of fundamental rights, regardless of feature and even though not expressly contained in the text. Nevertheless, it is undeniable the difficulty faced when it comes to social rights, characterized by requiring positive benefits from the State. Given these projections, examines if the principle of possible reserve can be applied to the Brazilian legal system in order to justify certain tragic choices, and its connection with the concept of existential minimum. Finally, studies the important discussion about the
\end{abstract}

1 Bacharel em Direito pela Universidade Federal do Ceará. Advogado. Atuação relacionada à efetivação e proteção dos direitos humanos. Aprovado no concurso público para Defensor Público do Estado do Maranhão. 
possibility and the limits of the judicial role in controlling these policies developed by the Executive and Legislative.

Keywords: Fundamental social rights; Effectiveness. Possible reserve; Existential minimum; Public policy; Judicial control.

\section{Introdução}

A problemática da eficácia dos direitos fundamentais sociais é um dos maiores desafios enfrentados, não somente pelo Judiciário, mas, por toda a sociedade nos dias atuais. Os direitos sociais, contrariamente aos direitos de defesa, demandam um facere, consubstanciado em prestações positivas por parte do Estado em benefício do indivíduo. E é aqui, no seu caráter mais digno e realizador, que reside sua maior deficiência: a dificuldade em efetivá-los.

A efetivação desses direitos depende da existência de recursos financeiros, da disponibilidade econômica do Estado ou de instrumentos jurídicos capazes de satisfazê-los. É preciso, dessa forma, fortalecer o debate acerca da elaboração do orçamento, da alocação de recursos em áreas prioritárias, tornando mais legítimas as escolhas feitas pelo Executivo e Legislativo.

Ocorre que, diante da ineficiência na efetivação dos direitos sociais por parte do governo e do parlamento, o Judiciário passou a ter um papel de destaque na consecução desse desiderato. Inúmeras críticas são lançadas a esse ativismo, uma vez que a competência para definir as políticas públicas e a sua execução orçamentária correspondente pertence, em regra, ao Poder Executivo.

Diante desse quadro, o presente artigo busca analisar a problemática da efetivação dos direitos fundamentais, a importância e a possibilidade da atuação judicial no controle das políticas públicas, a alegação da reserva do possível como forma de legitimação de escolhas trágicas, bem como a estruturação da separação dos poderes em face desse novo panorama. 


\section{A evolução dos direitos fundamentais}

\subsection{As diversas dimensões dos direitos fundamentais}

Nas palavras de Dirley da Cunha Júnior, "é inegável que o grau de democracia em um país mede-se precisamente pela expansão dos direitos fundamentais e por sua afirmação em juízo" (CUNHA JÚNIOR, 2010, p. 533). Não é possível, assim, dissociar democracia e efetivação de direitos fundamentais. Dessa forma, os direitos fundamentais devem ser considerados o núcleo essencial da democracia constitucional.

Diante dessa constatação, é possível visualizar os direitos fundamentais como posições jurídicas que investem os indivíduos de prerrogativas e faculdades indispensáveis a assegurar uma existência digna.

George Marmelstein os retrata como:

[...] normas jurídicas, intimamente ligadas à ideia de dignidade da pessoa humana e de limitação do poder, positivadas no plano constitucional de determinado Estado Democrático de Direito, que, por sua importância axiológica, fundamentam e legitimam todo o ordenamento jurídico (MARMELSTEIN, 2011, p. 20).

Os direitos fundamentais vêm sendo sedimentados ao longo do tempo. O seu progressivo reconhecimento consiste num processo cumulativo, de complementaridade, não havendo supressão temporal de direitos anteriormente reconhecidos.

Nas palavras de Paulo Bonavides:

A história dos direitos humanos - direitos fundamentais de três gerações sucessivas e cumulativas, a saber, direitos individuais, direitos sociais e direitos difusos - é a história mesma da liberdade moderna, da separação e limitação de poderes, da criação de mecanismos que auxiliam o homem a concretizar valores cuja identidade jaz primeiro na Sociedade e não nas esferas do poder estatal (BONAVIDES, 2000, p. 528).

Diante dessa ideia, foram reconhecidas gerações ou dimensões de direitos fundamentais, as quais revelam a ordem cronológica do reconhecimento e afirmação dos mesmos, frutos da mudança das condições sociais.

Os direitos fundamentais de primeira dimensão foram os primeiros direitos solenemente reconhecidos, resultando do pensamento liberal-burguês da época. Caracterizam-se por serem marcadamente individualistas, afirmando-se como direitos do 
indivíduo frente ao Estado. Esses direitos correspondem às liberdades públicas, compreendendo os direitos civis, à vida, à liberdade, à propriedade e os direitos políticos.

Ocorre que importantes transformações econômicas e sociais alteraram profundamente o quadro em que se inseria o pensamento liberal. Nesse contexto, surgiu o Estado do Bem-Estar Social, caracterizado por ações positivas e intervencionistas. Consagram-se, assim, os direitos de segunda dimensão, que consistem em direitos econômicos, sociais e culturais.

Esses direitos exigem prestações positivas por parte do Estado, reclamando uma intervenção estatal para o fornecimento de prestações fáticas e jurídicas. As normas constitucionais sobre os direitos de segunda geração são classificadas como normas programáticas, definindo metas e objetivos que precisam ser concretizados pelo legislador. Dessa forma, tais direitos dependem não só de regulamentação, mas da elaboração de políticas públicas, as quais, por outro lado, ficam submetidas à existência de recursos materiais e financeiros.

Por sua vez, os direitos de terceira dimensão caracterizam-se por almejarem a proteção não apenas do indivíduo, mas da coletividade social, possuindo titularidade coletiva ou difusa. Englobam o direito à paz, à solidariedade, ao meio-ambiente equilibrado, à comunicação, à autodeterminação dos povos e ao desenvolvimento.

Ademais, atualmente, pode-se afirmar a existência de uma quarta dimensão de direitos fundamentais. No escólio de Paulo Bonavides:

\begin{abstract}
Essa dimensão é o resultado da globalização dos direitos fundamentais, no sentido de uma universalização desses direitos no plano institucional, que corresponde à última fase da institucionalização do Estado Social. [...] Compreendem os direitos à democracia direta, ao pluralismo e à informação, que constituem a base de legitimação de uma possível globalização política e deles depende a concretização da sociedade aberta do futuro, em sua dimensão de máxima universalidade, para a qual parece o mundo inclinar-se no plano de todas as relações de convivência (BONAVIDES, 2000, p. 524-526).
\end{abstract}

Além dos direitos mencionados, também se deve reconhecer, como direitos de quarta dimensão, o direito contra manipulações genéticas, o direito à mudança de sexo e, em geral, os relacionados à biotecnologia. 


\section{Dos desafios institucionais para a realização dos direitos fundamentais sociais no contexto das políticas públicas}

Todavia, é importante frisar que essa distinção entre direitos de primeira e segunda dimensão é meramente gradual, nunca substancial, uma vez que muitos dos direitos fundamentais clássicos foram reinterpretados como sociais, ganhando uma nova roupagem.

Nesse sentido, Andréas Joachim Krell explica que:

No Estado moderno, os direitos fundamentais clássicos - os da primeira geração estão cada vez mais dependentes do poder público, deste reclamando prestações materiais sem as quais o indivíduo sofre sérias ameaças em sua liberdade (KRELL, 2002, p. 47).

E ressalta, ainda, que:

A doutrina moderna dá ênfase em afirmar que qualquer Direito Fundamental constitucional - seja ele direito civil e político ou econômico, social e cultural contém, ao mesmo tempo, componentes de obrigações positivas e negativas para o Estado. Nessa visão, a tradicional diferenciação entre os direitos 'da primeira' e os 'da segunda' geração é meramente gradual, mas não substancial, visto que muitos dos Direitos Fundamentais tradicionais foram reinterpretados como sociais, perdendo sentido as distinções rígidas (KRELL, 2000, p. 39).

Destarte, as diversas dimensões de direitos fundamentais não podem ser examinadas isoladamente, pois estão interligados na busca pela realização de seu desiderato.

\section{A eficácia dos direitos fundamentais}

Consoante prevê o artigo 5ำ, §1으, da Constituição Federal de 1988, "As normas definidoras de direitos e garantias fundamentais têm aplicação imediata" (BRASIL, 1988). Isso significa que, inicialmente, essas normas têm eficácia plena, não sendo dependentes de interposição do legislador para possuírem efetividade ou eficácia social.

Contudo, o tema não é pacífico, mormente pelo fato de que as normas definidoras de direitos fundamentais assumem contornos distintos. Dessa forma, não obstante todas as normas pertencerem à mesma categoria jurídico-normativa, não são dotadas da mesma carga eficacial, em virtude das diferentes funções que exercem e das distintas técnicas utilizadas para sua positivação.

Diante disso, surgiram inúmeras divergências quanto ao alcance da norma constitucional supracitada. Uma primeira posição, capitaneada por Manoel Gonçalves 
Ferreira Filho, nega a possibilidade de aplicação imediata dos direitos fundamentais, salvo quando as normas que os definem sejam completas na sua hipótese e no seu dispositivo.

Ingo Sarlet, por sua vez, busca uma solução intermediária, que, a um só tempo, não inviabilize o princípio da aplicação imediata dos direitos fundamentais nem o superestime, uma vez que, embora se aplique a todas as normas de direitos fundamentais, existem casos em que não se tem como dispensar uma concretização pelo legislador.

Por outro lado, Flávia Piovesan, Luís Roberto Barroso e Dirley da Cunha Júnior defendem a imediata aplicação dos direitos fundamentais, independentemente de intermediação legislativa. Nas palavras do professor fluminense, "a efetividade das normas constitucionais definidoras de direitos subjetivos pode e deve prescindir do mandado de injunção como instrumento de sua realização" (BARROSO, 2000, p. 263).

Afirma ainda, em relação ao princípio em tela, que:

Parece bem a sua inclusão no Texto, diante de uma prática que reiteradamente nega tal evidência. Por certo, a competência para aplicá-las, se descumpridas por seus destinatários, há de ser do Poder Judiciário. E mais: a ausência de lei integradora, quando não inviabilize integralmente a aplicação do preceito constitucional, não é empecilho à sua concretização pelo juiz, mesmo à luz do direito positivo vigente, consoante se extrai do art. 4으 da Lei de Introdução ao Código Civil [...] (BARROSO, 2000, p. 142-143).

Nessa esteira, Dirley da Cunha Júnior defende que:

\begin{abstract}
Em caso descumprimento, por omissão, de algum direito fundamental ou de lacuna legislativa impeditiva de sua fruição, deve e pode o Judiciário - valendo-se de um autêntico dever-poder de controle das omissões do poder público - desde logo e em processo de qualquer natureza, aplicar diretamente o preceito definidor do direito em questão, emprestando ao direito fundamental desfrute imediato, independentemente de qualquer providência de natureza legislativa ou administrativa. (CUNHA JÚNIOR, 2010, p. 629).
\end{abstract}

Não obstante a coerência e o acerto quanto à teoria da aplicação imediata dos direitos fundamentais, existe uma celeuma quando se fala de direitos sociais. Por demandarem prestações positivas do Estado, há quem não reconheça sua imediata eficácia, sendo este, o grande foco das discussões atuais. 


\title{
4 A problemática dos direitos sociais
}

Os direitos sociais surgiram diante da profunda crise de desigualdade social gerada pelo fracasso do Estado Liberal. Manifestam-se, assim, como concretizadores dos postulados da justiça social, outorgando aos indivíduos as prestações sociais de que necessitam para viver com dignidade.

A principal distinção entre os direitos sociais e os direitos de defesa é o seu objeto. Enquanto os direitos de defesa buscam uma abstenção do Estado, um non facere, exigindo deste prestações negativas, os direitos sociais têm por escopo um atuar do Estado, um facere, consubstanciado em prestações positivas em favor do indivíduo, assegurando-lhe o mínimo existencial.

Neste sentido, Ingo Wolfgang Sarlet versa que:

\begin{abstract}
Enquanto os direitos de defesa se identificam por sua natureza preponderantemente negativa, tendo por objeto abstenções do Estado, no sentido de proteger o indivíduo contra ingerências na sua autonomia pessoal, os direitos sociais prestacionais têm por objeto conduta positiva do Estado (ou particulares destinatários da norma), consistente numa prestação de natureza fática. Enquanto a função precípua dos direitos de defesa é a de limitar o poder estatal, os direitos sociais (como direitos a prestações) reclamam uma crescente posição ativa do Estado na esfera econômica e social. Diversamente dos direitos de defesa, mediante os quais se cuida de preservar e proteger determinada posição (conservação de uma situação existente), os direitos sociais de natureza positiva (prestacional) pressupõem seja criada ou colocada à disposição a prestação que constitui seu objeto, já que objetivam a realização da igualdade (SARLET, 2001, p. 261).
\end{abstract}

Sendo assim, ao necessitar da existência de recursos financeiros para sua concretização, parte da doutrina sustenta que os direitos sociais sujeitam-se a uma reserva do possível, entendida como a possibilidade de disposição econômica e jurídica por parte do destinatário da norma.

Ademais, alegam que os direitos sociais também dependem de concretização legislativa, uma vez que, não dispondo de conteúdo normativo determinado e consistente, apenas o legislador poderia conformá-los.

Por outro lado, existem doutrinadores que acreditam que os direitos sociais possuem o mesmo nível de eficácia dos direitos individuais, sendo exigíveis todos os direitos classificados como fundamentais. Dessa forma, defendem que, embora exista uma distinção 
evidente no que se refere à estrutura normativa dos direitos de defesa e dos direitos sociais prestacionais, não há diferença entre seus regimes jurídicos.

Nesse sentido, Dirley da Cunha Júnior conclui que:

\begin{abstract}
A Constituição de 1988 avançou muito em relação aos direitos sociais. Pondo fim a uma discussão doutrinária estéril, inseriu os direitos sociais no título II que trata dos direitos fundamentais, não deixando mais qualquer dúvida quanto à natureza destes direitos: os direitos sociais são verdadeiros direitos fundamentais, com força normativa e vinculante, que investem os seus titulares de prerrogativas de exigir do Estado as prestações positivas indispensáveis à garantia do mínimo existencial. (CUNHA JÚNIOR, 2010, p. 722).
\end{abstract}

Apesar de um consenso não parecer tão próximo, podemos afirmar que os direitos sociais estão previstos, possuem eficácia e todos devem buscar sua efetivação de forma séria, diligente, sem invocação de argumentos falaciosos ou desculpas injustificáveis. É inegável que o papel do legislador ordinário e dos gestores públicos é essencial na escolha das políticas públicas adequadas e na concretização desses direitos, merecendo essas decisões um cuidado especial.

\title{
4 Das políticas públicas
}

\subsection{Conceituação}

Os direitos sociais estão previstos na Constituição Federal de forma genérica, ampla e abstrata, demandando a atuação do Poder Público, mormente através dos Poderes Legislativo e Executivo, de forma a estabelecer os instrumentos e o momento adequado para implementá-los.

Diante disso, Américo Bedê Freire Júnior conceitua políticas públicas como "um conjunto ou medida isolada praticada pelo Estado com o desiderato de dar efetividade aos direitos fundamentais ou ao Estado Democrático de Direito" (FREIRE JÚNIOR, 2005, p. 47).

As políticas públicas podem ser entendidas como os meios necessários à efetivação dos direitos sociais que, por sua natureza, pressupõem uma atuação incisiva dos poderes públicos.

Versando sobre o tema, Ronald Dworkin define políticas públicas como: 


\section{Dos desafios institucionais para a realização dos direitos fundamentais sociais no contexto das}

políticas públicas

Aquele tipo de padrão que estabelece um objetivo a ser alcançado, em geral, uma melhoria em algum aspecto econômico, político ou social da comunidade (ainda que certos objetivos sejam negativos pelo fato de estipularem que algum estado atual deva ser protegido contra mudanças adversas). (DWORKIN, 2002, p. 37).

Nota-se, diante disso, que as políticas públicas constituem uma maneira de efetivar o acesso das camadas mais desfavorecidas aos direitos fundamentais de cunho social. Dessa forma, o Estado, gerindo os interesses da sociedade, define, por meio dos Poderes Legislativo e Executivo, as metas e os instrumentos de interesse da comunidade. As políticas públicas, assim, revelam-se como uma intervenção do poder público na vida social.

Nesse diapasão, Eduardo Appio argumenta que:

As políticas públicas implementadas pelo Estado brasileiro podem ser consideradas setoriais, na medida em que atingem determinados segmentos da sociedade, a partir de necessidades específicas. [...] As chamadas políticas de inclusão têm por finalidade assegurar o acesso efetivo de segmentos pouco representados da população aos bens sociais fundamentais, com o que se reduz o impacto de um modelo puro de democracia representativa (APPIO, 2007, p. 115).

Destarte, políticas públicas são atividades predominantemente administrativas que tomam forma através de programas de atuação do governo, os quais buscam definir as áreas sociais que devem ser priorizadas, planejar os objetivos a serem alcançados, analisar os instrumentos disponíveis e o momento azado para sua realização, bem como direcionar os recursos públicos necessários para a consecução desses objetivos.

\subsection{Reserva do possível}

A dimensão econômica dos direitos é realidade inafastável que não pode ser colocada à margem da discussão. Não há como negar o entrelaçamento entre efetivação dos direitos fundamentais sociais e existência de recursos públicos para realizá-los.

Analisando-se a realidade nacional, verifica-se que, em grande parte, os direitos sociais necessitam de regulamentação por meio de políticas públicas, que dependem, substancialmente, das possibilidades financeiras dos entes federativos para serem implementadas. Sendo assim, o planejamento da atividade financeira ocorre através do orçamento, que consiste no instrumento de ação do Estado que fixa os objetivos a serem atingidos. 
Diante desse panorama, parte da doutrina alega que há diversos conflitos por recursos escassos, uma vez que a realização plena e incondicional de todos os direitos sociais não passa de uma utopia. Assim, afirmam que a questão dos custos dos direitos age como limite fático à concretização dos direitos sociais. Esse argumento da escassez dos recursos como restrição ao reconhecimento do direito social é denominado cláusula da reserva do possível.

A reserva do possível é, dessa forma, sinônimo de razoabilidade econômica ou proporcionalidade financeira. É aquilo que o indivíduo pode razoavelmente exigir da coletividade. Nas palavras de George Marmelstein, "A reserva do possível é uma limitação lógica e, de certo modo, óbvia à atividade jurisdicional em matéria de efetivação dos direitos econômicos, sociais e culturais. Afinal, sem dinheiro não há como realizar diversos direitos" (MARMELSTEIN, 2011, p. 356).

No Brasil, a cláusula da reserva do possível é constantemente invocada como barreira intransponível à efetivação dos direitos sociais. De forma cômoda, a doutrina nacional, lamentavelmente, aceita-a indiscriminadamente, maculando os valores constitucionais.

Vale ressaltar que a escassez de recursos para realização dos direitos fundamentais sociais é, em grande parte, fruto de escolhas alocativas dos poderes públicos que podem ser objeto de ponderação se, constatada, eventual desproporcionalidade.

Com isso, não se pretende desconsiderar a dimensão econômica do direito. Por óbvio, quando restar demonstrado equilíbrio, razoabilidade e observância dos preceitos constitucionais no processo de alocações orçamentárias, tem-se por legítima a alegação da cláusula da reserva do possível para relativizar a exigibilidade do direito social. Em outras palavras, a escassez deve ser necessária e proporcional.

Nesse sentido, vale citar trecho do voto do Ministro Celso de Mello no julgamento da ADPF 45/2004:

A cláusula da 'reserva do possível' - ressalvada a ocorrência de justo motivo objetivamente aferível - não pode ser invocada, pelo Estado, com a finalidade de exonerar-se do cumprimento de suas obrigações constitucionais, em particular quando, dessa conduta governamental negativa, puder resultar nulificação ou, até mesmo, aniquilação de direitos constitucionais impregnados de um sentido de essencial fundamentalidade (STF, ADPF 45/2004, rel. Celso de Mello, 01/07/2004). 


\section{Dos desafios institucionais para a realização dos direitos fundamentais sociais no contexto das} políticas públicas

Entretanto, o que se observa é que, apesar da reserva do possível ser uma limitação lógica à possibilidade de efetivação dos direitos sociais, o que vem ocorrendo é uma banalização na sua utilização por parte do Poder Público quando em juízo, que normalmente se furta em apresentar elementos concretos a respeito da impossibilidade material de se cumprir decisões judiciais nesse sentido.

Assim, não há como entender diferentemente que o argumento da reserva do possível somente deve ser observado se o Poder Público demonstrar suficientemente que a decisão causará mais danos do que benefícios à concretização dos direitos fundamentais. Em suma, é do Poder Público o ônus probatório de que não há recursos para efetivar esses direitos.

\subsection{Mínimo Existencial}

É patente na doutrina e na jurisprudência que a temática da eficácia imediata dos direitos fundamentais sociais está longe de estar pacificada. Apesar disso, mesmo os que não defendem a possibilidade de aplicação imediata desses direitos, reconhecem que o Estado é obrigado a assegurar aos cidadãos pelo menos as condições mínimas para uma existência digna. É a chamada "teoria do mínimo existencial".

Por essa teoria, somente o núcleo essencial dos direitos sociais teria um grau de fundamentalidade capaz de gerar, por si só, direitos subjetivos aos respectivos titulares. Estando a pretensão fora do mínimo existencial, o reconhecimento de direitos subjetivos dependeria da legislação infraconstitucional a regulamentar a matéria, não podendo, por exemplo, o Judiciário agir além da previsão legal.

Nas palavras de Ana Paula de Barcellos, o mínimo existencial corresponderia a:

\footnotetext{
Um elemento constitucional essencial, pelo qual se deve garantir um conjunto de necessidades básicas do indivíduo, um núcleo irredutível do princípio da dignidade da pessoa humana, o qual incluiria um mínimo de quatro elementos de natureza prestacional: a educação fundamental, a saúde básica, a assistência aos desamparados e o acesso à justiça (BARCELLOS, 2002, p. 126).
}

Porém, deve-se ter o cuidado de não se permitir, ao interpretar esse princípio, que se esvazie a força jurídica desses direitos, diminuindo-se ao máximo o seu conteúdo 
"essencial", uma vez que doutrina e jurisprudência se encarregarão de definir os contornos desse "conteúdo mínimo".

$\mathrm{Na}$ verdade, o mínimo existencial assume o caráter de regra e, por via de consequência, não está sujeito à ponderação. Dessa forma, em relação ao mínimo existencial, não se vislumbra a possibilidade de ponderação baseada na escassez de recursos (reserva do possível), já que se trata de garantia de proteção mínima dos direitos sociais, indispensável à sobrevivência do titular com dignidade.

\section{0 controle das políticas públicas pelo Poder Judiciário}

Diante do até agora exposto, claramente está comprovado que os direitos fundamentais se encontram reconhecidos constitucionalmente como direitos subjetivos de aplicação imediata. Desta feita, atestada sua magnitude para a ordem constitucional, sua efetividade não pode depender de decisões políticas do Legislativo ou Executivo, o que legitima uma maior interferência judicial na busca pela concretização máxima dessas normas, mesmo na falta de regulamentação infraconstitucional.

Uma das mais acaloradas discussões na seara do direito constitucional é saber se os direitos fundamentais que demandam prestações positivas podem ser efetivados pelo Poder Judiciário sem a prévia intervenção legislativa. Sobre o tema, elucidativas são as palavras de George Marmelstein:

Há, no caso, um conflito entre o princípio da máxima efetividade dos direitos fundamentais (que exige do Judiciário uma postura ativa em favor desses direitos) e os princípios da separação dos poderes e da democracia representativa (que pressupõem que as decisões políticas sejam tomadas por representantes eleitos pelo povo e não pelos juízes) (MARMELSTEIN, 2011, p. 345).

Com a evolução da sociedade, as relações sociais vêm se tornando cada vez mais complexas, inclusive em relação ao questionamento das políticas públicas adotadas pelos representantes populares no exercício de suas funções, de forma que o Poder Judiciário, de maneira progressiva, foi sendo acionado para se manifestar acerca dos direitos existentes nas controvérsias políticas, numa visão democrática do Estado de Direito.

Nesse contexto, a concepção clássica de tripartição dos poderes vem sendo reavaliada, numa clara postura de se efetivar os direitos garantidos nas Constituições dos 
Estados contemporâneos, demandando um Poder Judiciário mais atuante e responsável na concretização do Estado Democrático de Direito, uma vez que não se pode mais aceitar a ideia de entregar a alguém um poder absoluto sobre determinada função pública, mormente o de formular e implementar políticas públicas.

Esse pensamento deriva da ideia de que a Constituição de uma sociedade possui força normativa suficiente para assegurar a plena aplicabilidade de suas normas, obstando a violação de seus dispositivos, em respeito à primazia da supremacia da Constituição.

Diante da crescente judicialização da política, mostrou-se inevitável o surgimento de conflitos de interesses e tensões entre os poderes. De um lado, há quem defenda um Poder Judiciário mais atuante nas questões políticas do Estado. De outro, existem ferrenhos defensores da autonomia total dos poderes instituídos, legando ao Judiciário uma função mais contida.

Para o primeiro grupo, o Poder Judiciário deve atuar de maneira ativa como um protetor dos princípios fundamentais, do Estado Democrático de Direito e como um veículo de transformação social do país, com o intuito de sedimentar a igualdade material entre a sociedade, sem prejuízo da liberdade.

Por outro lado, o segundo grupo alega que a atuação do Poder Judiciário no controle de políticas públicas desrespeita o processo democrático, uma vez que é através dele que são eleitos os seus representantes para a elaboração das atividades necessárias à coletividade, não sendo o Judiciário o palco mais adequado para a discussão dos conflitos político-sociais, uma vez que somente os poderes eleitos pelo povo têm legitimidade para realizar essas escolhas.

Contudo, esse pensamento não deve mais encontrar guarida no contexto moderno, especialmente em face da força normativa da Constituição. Nas palavras de Jean Carlos Dias, "a atuação do Judiciário não somente não compromete uma concepção forte e substancial de democracia, como também permite que esta seja, sem dúvida alguma, levada ao seu estado mais elevado" (DIAS, 2007, p. 98).

Ainda nessa esteira, afirma o autor:

Naturalmente, isso não significa que caiba aos tribunais eleger os meios de ação política e os objetivos que se pretendem alcançar, mas, sobretudo, permitir que, nas disputas a respeito, a base para a análise de um conflito desloque-se do campo 
puramente político fundado na preocupação eleitoral e passe para o campo jurídico, tendo em vista a observância dos direitos e deveres consagrados no âmbito legal e constitucional. Essa possibilidade é claramente desejável quando uma política acaba por conflitar-se com um direito fundamental (DIAS, 2007, p. 158-159).

No mesmo sentido, Lênio Luiz Streck defende que:

Ao argumento de que a concretização de direitos via judiciário (jurisdição constitucional) enfraquece a cidadania e coloca em risco a própria democracia, cabe lembrar que não há qualquer registro de que a democracia brasileira tenha sido colocada em xeque em face de decisões judiciárias concessivas de direitos, consideradas como 'jurisprudência de valores', 'ativismo judicial' etc.

Ao contrário, há um conjunto de avanços sociais, fruto de pressões de movimentos sociais, que tem recebido o selo jurídico, a partir da jurisprudência dos tribunais e, em determinadas situações, 'convalidadas' por legislações emanadas do Poder Legislativo (STRECK, 2006, p. 114).

O princípio da separação dos poderes merece uma releitura em sintonia com a teoria dos direitos fundamentais e do Estado Democrático de Direito, permitindo um eficiente sistema de "freios e contrapesos", não podendo se transformar em um obstáculo às reivindicações de cunho social, uma vez que a separação dos poderes não constitui um fim em si mesmo, nem possui um modelo apriorístico ideal, sendo uma forma de conexão entre as funções estatais em busca da preservação dos direitos fundamentais.

Destarte, é papel do Judiciário intervir nos poderes Executivo e Legislativo quando esses violarem direitos fundamentais. Esses direitos precisam ser protegidos do abuso e arbítrio estatal, mas, também e especialmente, de sua omissão. É dever do Estado proporcionar um diálogo entre todas as suas funções a fim de garantir tal proteção. Vale ressaltar que não se defende, assim, a supremacia de uma função estatal sobre as outras, mas a supremacia da própria Constituição.

O Poder Judiciário tem a função de zelar pelo cumprimento da Constituição e pela concretização da "justiça social". Com isso, não se quer afirmar que o controle judicial deve ocorrer em todas as hipóteses e circunstâncias, mas, sim, que, em casos excepcionais de flagrante violação dos direitos fundamentais, sua atuação é rigor.

No escólio de Aury Lopes Júnior:

A legitimidade democrática do juiz deriva do caráter democrático da Constituição, e não da vontade da maioria. O juiz tem uma nova posição dentro do Estado de 


\section{Dos desafios institucionais para a realização dos direitos fundamentais sociais no contexto das políticas públicas}

Direito e a legitimidade de sua atuação não é política, mas constitucional, e seu fundamento é unicamente a intangibilidade dos direitos fundamentais. É uma legitimidade democrática, fundada na garantia dos direitos fundamentais e baseada na democracia substancial." (LOPES JÚNIOR, 2004, p. 73).

Desta feita, omitindo-se o Legislativo e o Executivo ou não cumprindo de forma efetiva suas obrigações, caberá uma postura ativa do Judiciário, exigindo deles a disponibilização de serviços públicos, bem como a melhoria na sua qualidade. Porém, em caso de inércia injustificada desses poderes, deverá o Judiciário impor-Ihes penalidades, fazendo valer a força normativa da Constituição na consecução dos seus objetivos.

\section{Conclusão}

O advento de novas categorias de direitos, especialmente os sociais, vem obrigando o Executivo, Legislativo e mesmo o Judiciário a dar respostas mais efetivas e imediatas, sendo o controle judicial das políticas públicas uma via pela qual não se pode mais retroceder, sob pena de afrontar a força normativa da Constituição.

Desta feita, torna-se impossível negar a possibilidade de controle judicial das políticas públicas, não sendo correto cogitar acerca da ausência de legitimidade do Poder Judiciário para a implementação dessas medidas ou de violação ao princípio da separação dos poderes, até mesmo porque a legitimidade do controle por parte do Poder Judiciário advém do próprio texto constitucional.

Diante disso, é imperioso reconhecer que existe uma vinculação entre os poderes estatais, a qual impõe o controle, ainda que excepcional, pelo Poder Judiciário dos demais poderes, quando esses se quedarem inertes, em clara violação aos direitos fundamentais, buscando sempre a afirmação da supremacia da Constituição.

Ademais, o controle judicial das políticas públicas não interfere no juízo de conveniência e oportunidade do Administrador Público, uma vez que não há discricionariedade no descumprimento da Constituição. Não se pode barganhar acerca dos direitos fundamentais, caracterizando-se as políticas públicas como um dever da Administração que deve ser cumprido.

Diante disso, resta claro que não se pode mais conceber as normas definidoras de direitos fundamentais sociais como simplesmente programáticas, apenas definindo objetivos 
e finalidades a serem concretizadas pelo legislador ordinário. Por conseguinte, devem ser imediatamente aplicáveis e exigíveis pelos cidadãos, independentemente de regulamentação, assim como os demais direitos fundamentais, nos termos da Constituição Federal.

Portanto, o Poder Judiciário exerce um papel de destaque na atual conjuntura político-jurídica de nosso país. É imperiosa a sua participação na transformação da realidade social, mormente pelo fato de que temos um país em que a desigualdade é vista em cada esquina, sentida em cada afronta aos mais necessitados. O Judiciário tem o dever de ser um valioso instrumento para que finalmente possamos realizar o princípio da dignidade da pessoa humana, baluarte de nosso ordenamento jurídico. Negar isso é fechar os olhos para um sentimento básico que permeia e inspira toda a teoria dos direitos humanos: a solidariedade.

\section{Referências}

APPIO, Eduardo. Discricionariedade Política do Poder Judiciário. 2. ed. Curitiba: Juruá, 2007.

BARCELLOS, Ana Paula de. A Eficácia Jurídica dos Princípios Constitucionais. O princípio da dignidade da pessoa humana. Rio de Janeiro: Renovar, 2002.

BARROSO, Luís Roberto. O Direito Constitucional e a efetividade de suas normas: limites $e$ possibilidades da Constituição Brasileira. 4. ed., amp. e atual. Rio de Janeiro: Renovar, 2000.

BONAVIDES, Paulo. Curso de Direito Constitucional. 9. ed. São Paulo: Malheiros, 2000.

BRASIL. Constituição da República Federativa do Brasil. Brasília, DF, Senado, 1988.

CUNHA JÚNIOR, Dirley da. Curso de Direito Constitucional. 4. ed. Salvador: Juspodivm, 2010.

DIAS, Jean Carlos. O controle judicial de políticas públicas. São Paulo: Método, 2007. (Coleção Professor Gilmar Mendes; v.4).

DWORKIN, Ronald. Levando os direitos a sério. São Paulo: Martins Fontes, 2002.

FREIRE JÚNIOR, Américo Bedê. O controle judicial de políticas públicas. São Paulo: Revista dos Tribunais, 2005. (Coleção temas fundamentais de direito; v. 1). 
Dos desafios institucionais para a realização dos direitos fundamentais sociais no contexto das políticas públicas

KRELL, Andréas Joachim. Controle judicial dos serviços públicos básicos na base dos direitos fundamentais sociais. In: SARLET, Ingo Wolfgang (Org.) A Constituição Concretizada: Construindo pontes com o público e o privado. Porto Alegre: Livraria do Advogado, 2000.

. Direitos sociais e controle judicial no Brasil e na Alemanha: os (des) caminhos de um Direito Constitucional "comparado". Porto Alegre: Sergio Antonio Fabris Editor, 2002.

LOPES JR., Aury. Introdução crítica ao processo penal. Rio de Janeiro: Lúmen Júris, 2004.

MARMELSTEIN, George. Curso de direito fundamentais. 3. ed. São Paulo: Atlas, 2011.

SARLET, Ingo Wolfgang. A Eficácia dos Direitos Fundamentais. 2. ed. Porto Alegre: Livraria do Advogado, 2001.

SARMENTO, Daniel. Direitos fundamentais e Relações privadas. Rio de Janeiro: Lumen Juris, 2004.

STRECK, Lênio Luiz. Verdade e consenso. Rio de Janeiro: Lúmen Júris, 2006.

TAVARES, André Ramos. Curso de Direito Constitucional. 5. ed. São Paulo: Saraiva, 2007.

Artigo recebido em 28/03/2012 e aprovado para publicação em 26/04/2012. 
